\title{
The endothelial glycocalyx: composition, functions, and visualization
}

\author{
Sietze Reitsma • Dick W. Slaaf • Hans Vink • \\ Marc A. M. J. van Zandvoort • \\ Mirjam G. A. oude Egbrink
}

Received: 4 October 2006 / Accepted: 9 January 2007 / Published online: 26 January 2007

(C) Springer-Verlag 2007

\begin{abstract}
This review aims at presenting state-of-the-art knowledge on the composition and functions of the endothelial glycocalyx. The endothelial glycocalyx is a network of membrane-bound proteoglycans and glycoproteins, covering the endothelium luminally. Both endothelium- and plasmaderived soluble molecules integrate into this mesh. Over the past decade, insight has been gained into the role of the glycocalyx in vascular physiology and pathology, including mechanotransduction, hemostasis, signaling, and blood cellvessel wall interactions. The contribution of the glycocalyx to diabetes, ischemia/reperfusion, and atherosclerosis is also reviewed. Experimental data from the micro- and macrocirculation alludes at a vasculoprotective role for the glycocalyx. Assessing this possible role of the endothelial glycocalyx requires reliable visualization of this delicate layer, which is a great challenge. An overview is given of the various ways in which the endothelial glycocalyx has been visualized up to now, including first data from two-photon microscopic imaging.
\end{abstract}

S. Reitsma $\cdot$ D. W. Slaaf $\cdot$ M. A. M. J. van Zandvoort

Department of Biophysics, Cardiovascular Research Institute Maastricht (CARIM), Maastricht University,

Maastricht, The Netherlands

\section{W. Slaaf}

Department of Biomedical Engineering, Technische Universiteit Eindhoven, Eindhoven, The Netherlands

H. Vink $\cdot$ M. G. A. oude Egbrink $(\bowtie)$

Department of Physiology, Cardiovascular Research Institute

Maastricht (CARIM), Maastricht University,

P.O. Box 616, 6200 MD Maastricht, The Netherlands

e-mail: M.oudeEgbrink@FYS.unimaas.nl
Keywords Endothelial glycocalyx $\cdot$ Endothelial surface layer - Heparan sulfate - Hyaluronic acid - Vascular disease . Optical imaging $\cdot$ Two-photon microscopy

\section{Introduction}

The endothelial glycocalyx was already visualized some 40 years ago by Luft using electron microscopy [66]. Still, relatively little is known of the composition and function of this layer. Over the past decades, it has been increasingly appreciated as an important factor in vascular physiology and pathology, as described in 2000 in a review by Pries et al. [86] and in other, more recent reviews [4, 74]. The interest in the (patho)physiological role of the glycocalyx started with the observation of low and variable capillary tube hematocrit, which depended on the level of metabolic and pharmacological activation of the vascular system [51, $52,63,83,101]$. The relation between metabolic and agonist-induced increases in red blood cell velocity on the one hand and tube hematocrit on the other could partly be explained by plasma skimming as direct continuation of the Fåhraeus effect [83]. However, this relation dissociated upon local treatment of the microvessels with heparinase, an enzyme which breaks down heparan sulfates in the glycocalyx [17]. This finding was in agreement with theoretical estimates predicting a $1.2-\mu \mathrm{m}$ thick slowmoving plasma layer over the endothelium [51]. In vivo studies have revealed the glycocalyx in muscle capillaries to be a layer of about $0.5 \mu \mathrm{m}$ thick, covering endothelial cells and determining luminal domains for macromolecules, red and white blood cells [129]. More recent studies indicate that glycocalyx thickness increases with vascular diameter, at least in the arterial system, ranging from 2 to $3 \mu \mathrm{m}$ in small arteries [125] to $4.5 \mu \mathrm{m}$ in carotid arteries [67]. 
To date, many studies indicate a variety of (patho) physiological roles for the endothelial glycocalyx; in addition to modulating capillary red blood cell filling, the glycocalyx may affect many other (dys)functions of the vascular system. Whereas the vascular endothelium is currently believed to be actively involved "in every pathology presenting vascular projections" [28], the same saying might well prove true for the glycocalyx. Assessing this possible involvement of the endothelial glycocalyx requires reliable visualization of this delicate layer, which is a great challenge. This review provides basic insight into the present knowledge of composition and functions of the endothelial glycocalyx and gives an overview of the various ways in which it has been visualized up to now.

\section{Composition}

The endothelial glycocalyx is a carbohydrate-rich layer lining the vascular endothelium. It is considered to be connected to the endothelium through several "backbone" molecules, mainly proteoglycans and also glycoproteins. These form a network in which soluble molecules, either plasma- or endothelium-derived, are incorporated. More luminally, the glycocalyx is formed by soluble plasma components, linked to each other in a direct way or via soluble proteoglycans and/or glycosaminoglycans (which will be discussed below). A dynamic equilibrium exists between this layer of soluble components and the flowing blood, continuously affecting composition and thickness of the glycocalyx. Furthermore, the glycocalyx suffers from enzymatic or shear-induced shedding. The dynamic balance between biosynthesis and shedding makes it hard to define the glycocalyx geometrically [62]. The composition of the membrane-bound mesh of proteoglycans, glycoproteins, and glycosaminoglycans and the composition of associated plasma proteins and soluble glycosaminoglycans cannot be viewed as a static picture. Instead, the layer as a wholealso known as endothelial surface layer (ESL) [86] - is very dynamic, with membrane-bound molecules being constantly replaced and no distinct boundary between locally synthesized and associated elements; membrane-bound hyaluronan may reach lengths of $>1 \mu \mathrm{m}$. Direct visualization techniques (see section on Visualization techniques) fail to demonstrate clear compositional differences within the glycocalyx, from endothelial membrane towards vascular lumen, but rather indicate that the endothelial glycocalyx resembles an intricate, self-assembling 3D mesh of various polysaccharides. Enzymatic removal of any of its constituents dramatically affects glycocalyx properties, which exemplifies the importance of considering the synergetic interaction of all glycocalyx constituents as a whole. In this review we will, therefore, use the term (endothelial) glycocalyx for the total layer (Fig. 1) and be as specific as possible when addressing its various elements.

Below, state-of-the-art knowledge on the various components of the endothelial glycocalyx will be provided. Although many molecules have been identified as being part of the glycocalyx, information on their distribution is still scarce; if present, such knowledge was mostly obtained indirectly and nonquantitatively.

\section{Proteoglycans}

Proteoglycans are generally considered to function as the most important "backbone" molecules of the glycocalyx. They consist of a core protein to which one or more glycosaminoglycan chains are linked. There is a notable variation among the proteoglycan core proteins with regard to their size, number of attached glycosaminoglycan chains, and whether or not they are bound to the cell membrane (Table 1). The core protein groups of syndecans $(n=4)$ and glypicans $(n=6)$ have a firm connection to the cell membrane via a membrane-spanning domain (syndecans) or a glycosylphosphatidylinositol anchor (glypicans) [12, 25]. The other proteoglycans, such as mimecan, perlecan, and biglycan, are secreted after their assembly and glycosaminoglycan chain modification $[44,50]$. This leads to production of soluble proteoglycans, which reside in the glycocalyx or diffuse into the blood stream.

Proteoglycans are promiscuous in their binding of glycosaminoglycan chains, meaning that one core protein can contain different types of glycosaminoglycan chains. The proportion of the various chains may change under different circumstances and stimuli [89]. Therefore, naming of proteoglycans after one type of glycosaminoglycan is somewhat deluding. For example, syndecan-1 proteoglycan is often addressed as a heparan sulfate proteoglycan, while in fact, it usually contains similar numbers of heparan sulfate and chondroitin sulfate chains [70].

There are five types of glycosaminoglycan chains: heparan sulfate, chondroitin sulfate, dermatan sulfate, keratan sulfate, and hyaluronan (or hyaluronic acid). They are linear polymers of disaccharides with variable lengths that are modified by sulfation and/or (de)acetylation to a variable extent. The disaccharides are each composed of a uronic acid and a hexosamine; classification of the glycosaminoglycans depends on which uronic acid or hexosamine is incorporated and on the pattern of sulfation (Table 2). Each of the five glycosaminoglycans has been investigated and reviewed extensively [22, 27, 57, 58, 114]. Dermatan sulfate is often regarded as a separate class of glycosaminoglycans, although it actually is type B chondroitin sulfate. The difference between the two is possible epimerization of the glucuronic acids into iduronic acids in dermatan sulfate, which has important consequences for 


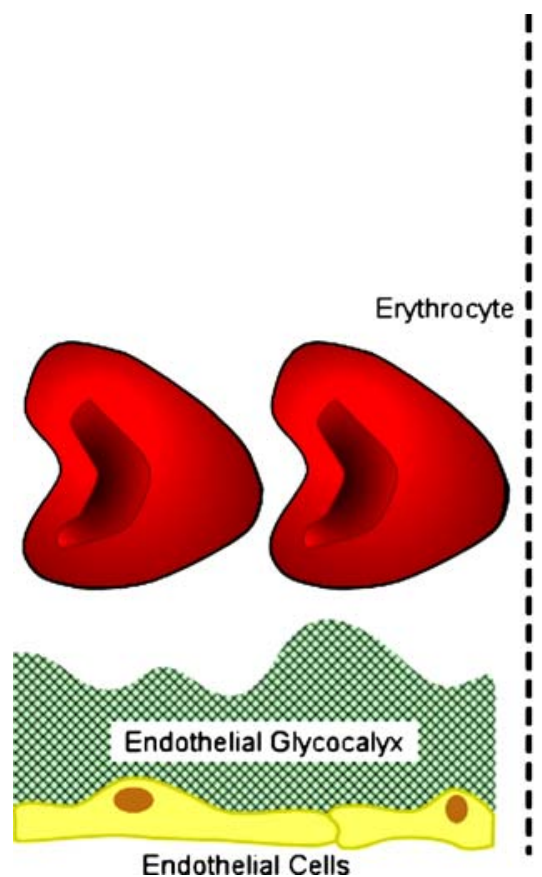

Fig. 1 Schematic representation of the endothelial glycocalyx, showing its main components. Left: The endothelial glycocalyx can be observed in vivo as a red blood cell exclusion zone, located on the luminal side of the vascular endothelium. It consists of membranebound and soluble molecules. Right: Components of the endothelial glycocalyx. Bound to the endothelial membrane are proteoglycans, with long unbranched glycosaminoglycan side-chains (GAG-chain) and glycoproteins, with short branched carbohydrate side-chains. Incorporated in and on top of this grid are plasma and endothelium-

functionality. Whenever possible, we will try to separate the two as precisely as possible; elsewhere, they will be referred to as chondroitin sulfate/dermatan sulfate.

In vasculature, heparan sulfate proteoglycans represent roughly $50-90 \%$ of the total amount of proteoglycans present in the glycocalyx $[43,86]$. However, this figure is variable, as the expression of proteoglycans by endothelial cells depends on various stimuli. Syndecans, for example, have a tightly regulated expression pattern which varies with endothelial cell activation or stimulation with different chemokines [119]. The second most common glycosaminoglycan in the endothelial cell glycocalyx is chondroitin

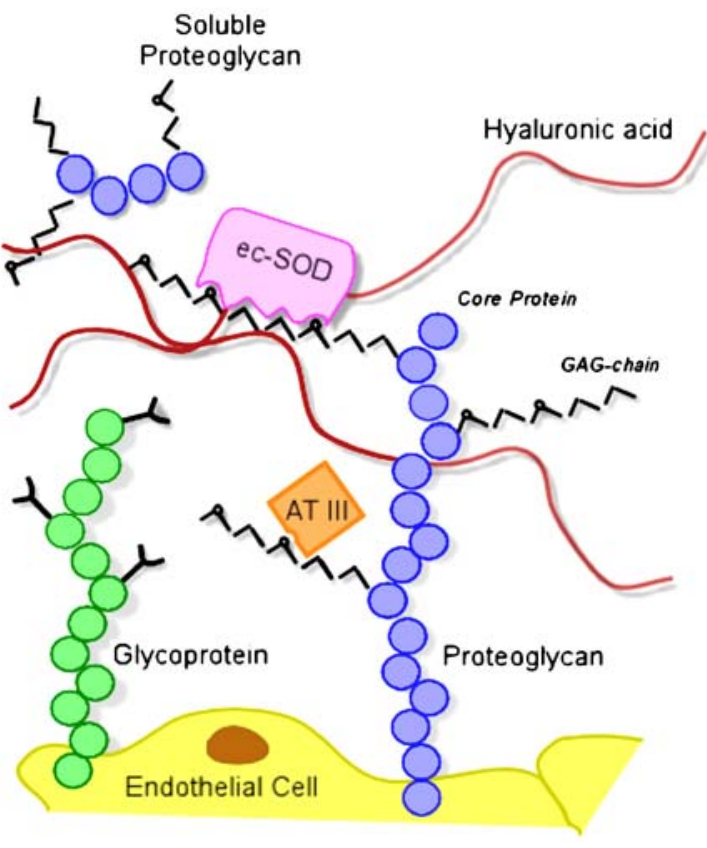

derived soluble components, including hyaluronic acid and other soluble proteoglycans (e.g., thrombomodulin) and various proteins, such as extracellular superoxide dismutase $(e c-S O D)$ and antithrombin III (AT III). Together, these components form the endothelial glycocalyx that functions as a barrier between blood plasma and the endothelium and exerts various roles in plasma and vessel wall homeostasis. Note that this figure is not drawn to scale; its purpose is to illustrate glycocalyx composition

sulfate/dermatan sulfate. The presence of heparan sulfate and chondroitin sulfate is reported to have a typical ratio of 4:1 for the vascular endothelium [70, 90]. Expression of keratan sulfate glycosaminoglycans in vasculature and its importance in (patho)physiology is less well understood. Another important glycosaminoglycan in the glycocalyx is hyaluronan. This long polymeric molecule (up to $10^{4} \mathrm{kDa}$ ) differs from other glycosaminoglycans in that it is not linked to a core protein. Its exact link to the cell membrane is unknown, but it can be bound to the receptor CD44 [72]. Alternatively, hyaluronan may be attached to its assembly proteins, the hyaluronan synthases [135], which are located

Table 1 Characteristics of proteoglycan core proteins in the vascular endothelial glycocalyx

\begin{tabular}{llllll}
\hline $\begin{array}{l}\text { Core protein } \\
\text { group }\end{array}$ & $\begin{array}{l}\text { Core protein size } \\
(\mathrm{kDa})\end{array}$ & $\begin{array}{l}\text { Number of } \\
\text { subtypes }\end{array}$ & $\begin{array}{l}\text { Number of GAG-chains } \\
\text { linked }\end{array}$ & $\begin{array}{l}\text { Type of GAG-chains } \\
\text { linked }\end{array}$ & $\begin{array}{l}\text { Structural relation } \\
\text { to cell membrane }\end{array}$ \\
\hline Syndecan & $19-35$ & 4 & 5 & HS/CS & Membrane-spanning \\
Glypican & $57-69$ & 6 & 3 & HS/CS & GPI-anchor \\
Perlecan & 400 & 1 & 3 & HS/CS & Secreted \\
Versican & 370 & 1 & $10-30$ & CS/DS & Secreted \\
Decorin & 40 & 1 & 1 & CS/DS & Secreted \\
Biglycan & 40 & 1 & 2 & KS & Secreted \\
Mimecan & 35 & 1 & $2-3$ & Secreted \\
\hline
\end{tabular}

$G A G$ Glycosaminoglycan, $H S$ heparan sulfate, $C S$ chondroitin sulfate, $D S$ dermatan sulfate, $K S$ keratan sulfate, GPI glycosylphosphatidylinositol 
Table 2 Composition of the disaccharides of various glycosaminoglycan chains

\begin{tabular}{llllll}
\hline & Heparan sulfate & Chondroitin sulfate & Dermatan sulfate $^{\text {a }}$ & Hyaluronan & Keratan sulfate \\
\hline Uronic acid & GlcA(2S) IdoA(2S) & GlcA & GlcA IdoA(2S) & GlcA & Gal(6S) \\
Disaccharide link & $1 \beta 4$ & $1 \beta 3$ & $1 \beta 3$ & $1 \beta 3$ & $1 \beta 4$ \\
Hexosamine & GlcNAc(NS)(3S)(6S) & GalNAc4S ${ }^{\text {a GalNAc6S }}{ }^{\text {a }}$ & GalNAc(4S)(6S) & GlcNAc & GlcNAc(6S) \\
Polymerization link & $1 \beta 4$ & $1 \beta 4$ & $1 \beta 4$ & $1 \beta 4$ & $1 \beta 3$ \\
\hline
\end{tabular}

Note the various possibilities of sulfation in heparan sulfate. These may coincide (e.g., in heparan sulfate the hexosamine GlcNS3S). A rare but possible hexosamine in heparan sulfate is the $N$-unsubstituted glucosamine $\left(\mathrm{GlNNH}_{3}^{+}\right)$, which has been left out of the table for convenient reading. Also note the presence of IdoA in dermatan sulfate, in contrast to the other chondroitin sulfates, making it more alike to heparan sulfate. GlcA Glucuronic acid, IdoA iduronic acid, Gal galacturonic acid, GlcNAc N-acetyl-glucosamine, GalNAc N-acetyl-galactosamine, $2 S$ 2-Osulfated, $3 S$ 3-O-sulfated, $4 S 4$ - $O$-sulfated, $6 S$ 6-O-sulfated, $N S N$-sulfated

${ }^{a}$ There are three types of chondroitin sulfate. Type A only has 4-O-sulfated $N$-acetyl-galactosamines, type B is known as dermatan sulfate and type $\mathrm{C}$ only has $6-\mathrm{O}$-sulfated $\mathrm{N}$-acetyl-galactosamines.

at the cytosolic side of the cell membrane. Another possibility is that hyaluronan is (in part) not directly bound to the membrane at all. It is capable of forming strikingly viscous solutions [57]. More recently, intracellular hyaluronan binding proteins such as cdc37 [31] and P32 [15] have been identified, suggesting a role for this glycosaminoglycan within the cell $[23,58]$.

Heparan sulfate and chondroitin sulfate/dermatan sulfate containing proteoglycans are produced in the endoplasmic reticulum and Golgi apparatus of the endothelial cell. After the ribosomal translation of the core protein, a xylosyltransferase will transfer xylose (Xyl) from uracildiphosphate xylose to specific serine residues (Ser) in the core protein. The xylose-enriched core protein is transported to the cisGolgi, and galactosyltransferases types I and II will add two galactose-groups (Gal) to the xylose, after which glucuronosyltransferase type I adds glucuronic acid, thus, completing the primary linker for glycosaminoglycan chains: -GlcA- $\beta 3-\mathrm{Gal}-\beta 3-\mathrm{Gal}-\beta 4-\mathrm{Xyl} \beta 3-[\mathrm{Ser}]$.

After formation of the primary linker, the following step determines the type of glycosaminoglycan chain that will be formed. In the case of heparan sulfate, an $\alpha 4$-glucosamine is added; in the case of chondroitin sulfate and dermatan sulfate, a $\beta 4$-galactosamine is added, and both galactose-residues from the linker may be sulfated. From this point onward, glucuronic acids and glucosamines are linked to the core protein. After chain polymerization, the growing glycosaminoglycan chain will undergo modifications including $N$-sulfation, $O$-sulfation, and epimerization. The latter changes glucuronic acid residues into iduronic acid residues and will change any chondroitin sulfate chain into its type B dermatan sulfate. These chain modifications take place in both the cis- and the trans-Golgi, determining the final type and functionality of the proteoglycan and each of its side chains. In contrast, hyaluronan is assembled at the cytosolic side of the cell membrane, and it is not modified afterwards. As a consequence, it has no sulfate groups or modification pattern.
As glycosaminoglycan chains contain numerous specific binding sites for plasma-derived proteins, small chain modifications can have great functional consequences. Sequential enzymatic modifications of the individual saccharide units within glycosaminoglycan chains endow proteoglycans with unique functions. Typically 16-48 different sulfation patterns may exist per disaccharide and as functional domains are assumed to be usually penta- to deca-saccharide long, at least $16^{3}=4,096$ different sulfation patterns on a hexasaccharide backbone are theoretically possible, and such a structural diversity corresponds to diversified biological functions of glycosaminoglycans. Indeed, it has been shown that modification patterns vary in time and under different (patho)physiological stimuli [4, 131]. The diversity of glycosaminoglycan sulfation patterns and its effect on specific protein binding and modulation of protein function suggest that conditions that diminish glycocalyx thickness or modulate protein specific glycosaminoglycan sulfation patterns and charge are likely to modulate vascular permeability and alter specific protein binding and activity.

\section{Glycoproteins}

Besides the proteoglycans with their long linear side chains, certain glycoproteins are also regarded as "backbone" molecules, connecting the glycocalyx to the endothelial cell membrane. This group of endothelial glycoproteins, characterized by relatively small (2-15 sugar residues) and branched carbohydrate side chains, comprises a number of molecules that all have been studied intensively; major classes that will be discussed in more detail below are the endothelial cell adhesion molecules and components of the coagulation and fibrinolysis system. It is beyond the scope of this review to categorically discuss all glycoproteins that can be expressed by endothelial cells. Furthermore, one should realize that the level of glycoprotein expression on the endothelial cell membrane varies considerably with cell activation or stimulation. 
The endothelial cell adhesion molecules are well-defined glycoproteins that play a major role in cell recruitment from the bloodstream and in cell signaling. The three families of cell adhesion molecules present in the endothelial glycocalyx are the selectin family, the integrin family, and the immunoglobulin superfamily.

Glycoproteins from the selectin family contain a cytoplasmic tail, a transmembrane domain, several consensus repeats, an epidermal growth factor-like domain, and a terminal lectin domain, which is primarily responsible for binding of carbohydrate groups on glycosylated proteins or lipids. However, the epidermal growth factor-like domain is involved in selectin-ligand recognition as well [29, 48]. Selectins found on the vascular endothelium are E-selectin and P-selectin, both involved in leukocyte-endothelial cell interactions [108]. P-selectin is constitutively produced and subsequently stored in the Weibel-Palade bodies of the endothelial cells. Exocytosis of Weibel-Palade bodies as induced by stimuli such as thrombin and histamine allows a rapid translocation of P-selectin to the cell surface $[19,53]$. However, this expression is short-lived due to P-selectin internalization and redirection to lysosomal granules or the Golgi apparatus, where it is restored in newly formed Weibel-Palade bodies [109]. E-selectin is not stored in granules, but requires de novo mRNA and protein synthesis to be expressed on the cell surface. Stimulation of endothelial cells by cytokines such as interleukin-1, tumor necrosis factor $\alpha$, and lipopolysaccharide upregulates E-selectin expression; this typically requires 2-6 h [47]. In some tissues like the skin, P- and E-selectin appear to be constitutively expressed on endothelial cells $[78,139]$.

Integrins are heterodimeric molecules, composed of non-covalently bound $\alpha$ and $\beta$ subunits. Both subunits have a cytoplasmic tail and a transmembrane domain, and together, they constitute an integral membrane protein. To date, 18 different $\alpha$-subunits and $8 \beta$-subunits have been identified, which means that each integrin is characterized by the specific combination of its subunits [142]. Integrins are found on many cell types, including endothelial cells, leukocytes, and platelets. In their luminal membrane, endothelial cells express integrin $\alpha_{\mathrm{V}} \beta_{3}$, which is an important mediator of platelet-endothelial cell interactions [11]. Most other endothelial cell integrins are involved in binding to the basement membrane. These integrins, such as $\alpha_{2} \beta_{1}, \alpha_{5} \beta_{1}$, and $\alpha_{6} \beta_{1}$, bind to multiple extracellular matrix ligands, and are as such, responsible for interactions with laminin, fibronectin, and collagen. Many studies have focused and still focus on the interactions between these integrins and the subendothelial matrix during angiogenesis [98].

The immunoglobulin superfamily of glycoproteins is characterized by a cytoplasmic tail, a transmembrane domain, and a variable number of immunoglobulin-like domains that protrude luminally. Best known examples are intercellular adhesion molecule 1 and 2 (ICAM-1 and -2), vascular cell adhesion molecule 1 (VCAM-1), and platelet/ endothelial cell adhesion molecule 1 (PECAM-1), which act as ligand for integrins on leukocytes and platelets and are crucial mediators of leukocyte homing to the endothelium and subsequent diapedesis. ICAM- 1 and -2 and PECAM-1 have a baseline expression, whereas VCAM-1 is only present after endothelial cell stimulation by cytokines, which also upregulates ICAM-1 expression [71]. Paradoxically, the constitutive expression of PECAM-1 is decreased after cytokine treatment [113]. The role of ICAM-2 in inflammation is still unclear, as it is also downregulated by inflammatory stimuli. Recently, it was shown that ICAM-2 is involved in regulation of angiogenesis [41].

Besides the cell adhesion molecules, the endothelial glycocalyx harbors glycoproteins with functionality in coagulation, fibrinolysis, and hemostasis. A good example is the glycoprotein Ib-IX-V complex, which is expressed on endothelial cells and also on platelets. It consists of four glycoproteins: $\mathrm{Ib} \alpha, \mathrm{Ib} \beta, \mathrm{IX}$, and $\mathrm{V}$, that are each membranespanning polypeptides. Glycoprotein $\operatorname{Ib} \alpha$ and $\operatorname{Ib} \beta$ are covalently linked via a disulfide group, whereas IX and V are non-covalently attached to the $\mathrm{Ib}$ heterodimer. The $\mathrm{Ib}-\mathrm{IX}-\mathrm{V}$ complex binds von Willebrand factor (vWf) and is primarily known as the platelet vWf-receptor $[65,99]$. Furthermore, the complex also binds P-selectin, mediating the interaction of platelets with activated endothelial cells [7]. Like platelets, endothelial cells express all components of the Ib-IX-V complex [115, 141], which on one hand, allows binding to the vWf substrate of the subendothelium, and on the other, binds Weibel-Palade body derived vWf, secreted luminally by activated endothelial cells.

\section{Soluble components}

Embedded within and layered on top of the mesh of proteoglycans and glycoproteins are soluble components of various types such as proteins and soluble proteoglycans. These components are either derived from the endothelium or from the bloodstream, such as albumin and orosomucoid, which are pivotal in preserving the (charge-)selectivity of the permeability barrier [42]. The soluble components of the glycocalyx contribute greatly to the functional importance of the glycocalyx, as will be described below. The structural attribution of these soluble components is less well established. At least some of the soluble components may contribute to the structural organization of the luminal glycocalyx, although this is hard to prove. There are indications that proteoglycans bind to each other and to proteins [54, 88]. Protein-glycosaminoglycan-protein complexes have been identified, although not in the glycocalyx in particular [145]. Still, it is presumable that interactions between membrane-bound proteoglycans, soluble proteins, and solu- 
ble proteoglycans create a cross-linked mesh and provide some stability to the luminal glycocalyx. Hyaluronan might play an important role in this respect, being a very large linear molecule and possibly unbound to the endothelial cell membrane (Fig. 1). It has been shown to interact with itself, forming stable hyaluronan-hyaluronan complexes [103, 104]. Still, the glycocalyx is a delicate layer, and removal of one specific component may result in loss of function of the total [117].

\section{Functional importance}

The endothelial glycocalyx as the endothelial gatekeeper

Located between the blood stream and the endothelium, the endothelial glycocalyx is an important determinant of vascular permeability $[35,130]$. It is able to limit access of certain molecules to the endothelial cell membrane, as has been demonstrated in small rat mesenteric arteries with the use of fluorescently labeled dextrans of various molecular weights, showing increasing permeability for smaller molecules [125]. Enzymatic (partial) removal and subsequent loss of permeability barrier function of the glycocalyx in rat myocardial capillaries leads to myocardial edema [124]. Not only size and steric hindrance play a role in glycocalyx dependent permeability, but also, electrostatic charges of the glycocalyx and the permeating substance. With many of the glycosaminoglycan chains being highly sulfated, the glycocalyx presents a net negatively charged surface to the bloodstream. Accordingly, neutralization of the glycocalyx induces an increase in albumin uptake by cultured endothelial cells [121] and an increased permeability for fluorescently labeled dextrans in rat mesenteric arteries [126].

The classical model used to describe microvascular fluid exchange is that of Starling [112], stating that fluid filtration rate across capillary endothelium is determined by the hydraulic and colloid osmotic pressures in the vascular lumen and in the surrounding tissue. This balance has been applied across the entire transendothelial barrier, with the different pressures being assessed globally. The discovery of a relatively thick endothelial glycocalyx and its influence on, e.g., edema formation has led to a major revision of the Starling principle by Weinbaum [137] and Michel [68], who proposed to apply the pressure gradients to the endothelial glycocalyx only. Hu and Weinbaum used this idea to generate a 3-D model of permeability over different regions of the endothelial layer, such as the glycocalyx, the endothelial clefts, and the tight junctions [40]. Recently, this model was simplified into a 1-D description of the varying tissue concentration gradients and subsequent permeability of the endothelium [144].
Another model, known as the glycocalyx-junction-break model, applies the Starling mechanism over the glycocalyx and describes its effects on solute and water transport over the endothelium, based on theoretical "pores" in the endothelium [79]. Recently, Curry has written a review on this model and the influences of phenotypical changes on microvascular permeability [14]. The importance of the endothelial glycocalyx in controlling extravasation of colloids and fluids is also stressed by studies of Rehm et al. [91] and Jacob et al. [45], who show impaired endothelial barrier function after glycocalyx degradation in an isolated, perfused heart model. Infusion of $5 \%$ albumin or $6 \%$ hydroxethyl starch, a natural and an artificial colloid, led to decreased fluid extravasation. However, after 20 mins of warm ischemia, only albumin infusion prevented vascular leakage. This underscores the importance of an intact glycocalyx and the role of plasmaderived proteins for competent glycocalyx functioning. The revised Starling principle has provided more detailed insight into vascular permeability and stresses the importance of the endothelial glycocalyx as a major determinant.

Besides its capacity to restrict molecules from reaching the endothelium, the glycocalyx also influences blood cell-vessel wall interactions. It repulses red blood cells from the endothelium. In the microcirculation, a red blood cell exclusion zone flanking the endothelium can be observed in vivo, which is decreased upon light dyeinduced breakdown of the glycocalyx [129]. Similarly, platelets are not often observed interacting with the endothelium in control conditions, whereas partial glycocalyx removal by infusion with oxidized low-density lipoprotein (ox-LDL) is accompanied by an increase in platelet-vessel wall interactions [128]. The role of the glycocalyx in leukocyte-vessel wall interactions seems dual: on the one hand, it harbors the endothelial cell adhesion molecules, such as P-selectin, ICAM-1, and VCAM-1; on the other hand, it attenuates adhesion of leukocytes to these molecules.

In healthy mouse cremaster muscle venules, breakdown of heparan sulfate side chains through heparitinase leads to an increase in leukocyte adhesion to the endothelium in a dose-dependent manner [13]. Administration of ox-LDL or $\mathrm{TNF} \alpha$ also induces leukocyte rolling and adhesion $[13,36]$. Steric hindrance seems to play a role in this process. The endothelial glycocalyx is much thicker (ranging from 0.2 $0.5 \mu \mathrm{m}$ in capillaries [124] to $2-3 \mu \mathrm{m}$ in small arteries [125] and $4.5 \mu \mathrm{m}$ in carotid arteries [67]) than the length of the various cell adhesion molecules. P-selectin, for example, the molecule initiating leukocyte rolling, only extends about $38 \mathrm{~nm}$ from the endothelial surface [111]. On cultured cells transfected with P-selectin constructs with two to six consensus repeats that are consequently shorter than normal P-selectin (nine consensus repeats), the number of attaching 
neutrophils decreased with decreasing P-selectin length. Cells defective of glycosylation, having a thinner glycocalyx, showed increased attachment of neutrophils [81]. Hence, in normal conditions, the glycosaminoglycan chains and soluble components of the glycocalyx seem to shield adhesion molecules, thereby, preventing interaction. Stimuli which degrade the glycocalyx or induce a more open mesh, such as enzymes, cytokines, or ischemia and reperfusion, appear to uncover the adhesion molecules, which in turn, allows blood cells to interact with the endothelium [13, 36, $70,128]$. One should realize that ligands for endothelial adhesion molecules are not uniformly distributed over the cell membrane of leukocytes, but show association with microvilli and membrane ruffles [102]. As the glycocalyx is estimated to have a low stiffness [33,106, 138], it is likely that the ligand bearing leukocyte membrane extensions protrude relatively easily into the glycocalyx to reach their receptor and enable leukocyte-vessel wall interaction. In contrast to other tissues, leukocyte-vessel wall interactions occur spontaneously in venules in the skin, even in normal conditions without preceding trauma or inflammation [46, 78]. Whether this is associated with a deviating glycocalyx structure and/or composition in skin microvessels remains to be elucidated.

The presence of a relatively thick endothelial glycocalyx in vivo has great consequences for rheology, especially in the microvasculature $[62,84]$. In this part of the circulation, local blood viscosity and hematocrit appear to be modulated by the glycocalyx. Using a physical model, based on hemodynamic and hematocrit measurements in microvascular networks in vivo, Pries and Secomb recently demonstrated that incorporation of realistic estimates of glycocalyx dimensions in reconstructed mesenteric microvascular networks introduces about a twofold increase in the apparent viscosity of blood. These changes are sufficient to minimize discrepancies between experimentally determined and theoretically predicted microvascular network resistances in previous studies, which were based on the apparent viscosity of blood in glycocalyx-devoid glass capillaries [85].

The endothelial glycocalyx as mechanotransducer

The endothelium is exposed to mechanical forces induced by blood flow. It has long been recognized that these forces, in particular, shear stress, determine endothelial cell morphology and function [16, 18]. Endothelial cells exposed to shear stress produce nitric oxide (NO) [96], which is an important determinant of vascular tone. However, the molecule(s) responsible for the translation of biomechanical forces into biochemical signals (mechanotransduction) have not been identified as yet. Recently, the glycocalyx has been added to the list of possible candidates. In studies with cultured endothelial cells, Florian and colleagues [24] showed that treatment with heparitinase to specifically break down heparan sulfate glycosaminoglycans results in inadequate responses to shear variations and impaired NO production. Similarly, ex vivo experiments on canine femoral arteries conducted by Mochizuki and coworkers exhibited reduced shear-induced NO production after infusion with hyaluronidase, which degrades the hyaluronan glycosaminoglycans in the glycocalyx [69]. Thus, both heparan sulfate and hyaluronan appear to play a role in detecting and amplifying flow-induced shear forces [69].

Interestingly, exposure of human umbilical vein endothelial cells to shear stress was found to increase the amount of hyaluronan in the glycocalyx approximately twofold, which may represent a positive feedback for shear stress sensing by endothelial cells [30]. Another recent study showed a correlation between shear stress profile and glycocalyx dimensions in the mouse carotid artery; the laminar flow profiles in the common carotid were found to coincide with a glycocalyx thickness of $399 \pm 174 \mathrm{~nm}$, whereas disturbed laminar flow in the sinus region of the carotid bifurcation coincided with a thinner glycocalyx of $73 \pm 36 \mathrm{~nm}$ [123]. Moreover, the flow divider region of the carotid bifurcation, supposedly having an undisturbed high laminar flow profile, was covered with a glycocalyx of $308 \pm 185 \mathrm{~nm}$, comparable to the common carotid glycocalyx thickness.

From these data, it seems likely that the glycocalyx plays an important role in mechanotransduction and that its composition is, in turn (at least partly), shear-dependent. The different components of the glycocalyx probably operate together, which means that the glycocalyx, as a whole, is responsible for its role as mechanotransducer. This idea is confirmed by theoretical models based on a regular hexagonal distribution of core proteins over the endothelial cell membrane [138]. Recently, Tarbell and Pahakis reviewed the current concepts on mechanotransduction by the (membrane-bound) glycocalyx [116]. They conclude that the glycocalyx core proteins are responsible for transmission of shear stress signals into specific cell signaling processes, e.g., NO production and cytoskeletal reorganization. At the same time, shear stress is transmitted to other regions of the endothelial cell as well, such as intercellular junctions and basal adhesion plaques, which are responsible for additional shear sensing even in the absence of a glycocalyx.

The endothelial glycocalyx as control center for the microenvironment

The proteoglycans in the glycocalyx contribute greatly to its functional importance. The glycosaminoglycan chain variety arising from chain epimerization, elongation, and most notably, chain sulfation, gives rise to a heterogeneous surface to which a lot of plasma-derived molecules can 
dock. Table 3 lists a number of molecules, which depend on interaction with the glycocalyx for their functionality.

Docking of plasma-derived molecules can influence the local environment in several ways: (1) Binding of receptors or enzymes and their ligands to the endothelial glycocalyx causes a localized rise in concentration of these substances, which enables proper signaling or enzymatic modification. Fibroblast growth factor (FGF) signaling is mediated in this way and is known to depend completely on the interaction of both ligand and receptor with the glycocalyx $[3,26]$. Similarly, the glycocalyx is involved in the lipolytic system, binding both lipoprotein lipase and its ligand low-density lipoprotein (LDL) [133, 140]. (2) Binding of plasma-derived molecules to the glycocalyx can lead to a local concentration gradient, which is often seen in growth factor-regulated gene transcription and developmental processes [61, 82]. (3) Docking of enzymes and their agonists or inhibitors to the glycocalyx adds a vasculoprotective role to glycocalyx functionality. Several important anticoagulant mediators can bind to the glycocalyx, such as antithrombin III, heparin cofactor II, thrombomodulin, and tissue factor pathway inhibitor (TFPI). Antithrombin III is a strong inhibitor of procoagulant enzymes like thrombin and activated factors $\mathrm{X}$ and IX (FXa and FIXa) [87]. It is known to bind to specific regions in heparan sulfate, which enhances its anticoagulant activity [107]. Heparin cofactor II is a thrombin-specific protease inhibitor [80], which is activated by dermatan sulfate in the glycocalyx [120]. Thrombomodulin is a chondroitin sulfate containing protein expressed by endothelial cells and is able to convert thrombin from a procoagulant enzyme to an activator of the protein $\mathrm{C}$ pathway, thus, becoming anticoagulant [136]. TFPI is a potent inhibitor of FVIIa and FXa. TFPI is believed to bind to the glycocalyx via heparan sulfates, but other proteins could be involved as well [49]. Furthermore, uptake and degradation of TFPIFXa complexes depends on heparan sulfates in the glycocalyx [38]. All these anticoagulant molecules present in the glycocalyx contribute to the thromboresistant nature of healthy endothelium [21]. The endothelial glycocalyx also modulates inflammatory responses by binding cytokines and attenuating binding of cytokines to cell surface receptors. Shedding of heparan sulfate from the glycocalyx results in increased endothelial cell sensitivity to activation by cytokines $[9,10]$. Another aspect of the vasculoprotective role of the endothelial glycocalyx is its capacity to bind quenchers of oxygen radicals, such as extracellular superoxide dismutase (SOD) [59]. These enzymes help to reduce the oxidative stress and keep up NO bioavailability, thus, preventing the endothelium from becoming dysfunctional.

The endothelial glycocalyx in pathophysiology

In healthy vessels, the endothelial glycocalyx determines vascular permeability, attenuates blood cell-vessel wall interactions, mediates shear stress sensing, enables balanced signaling, and fulfills a vasculoprotective role. But when it is disrupted or modified, these properties are lost, as has been shown through direct targeting of the glycocalyx in experimental settings. In the last few years, evidence is emerging that (damage to) the glycocalyx plays a pivotal role in several vascular pathologies. Here, we will discuss its suspected roles in diabetes, ischemia/reperfusion, and atherosclerosis.

\section{Diabetes}

Diabetes is a clinically well-known disease with far-reaching complications, such as retino- and nephropathy, and elevated

Table 3 Molecules dependent on interaction with the endothelial glycocalyx for proper functioning

\begin{tabular}{llc}
\hline Interacting molecule & Primary function in vasculature & Reference number \\
\hline Antithrombin III & $\begin{array}{c}\text { Potent inactivator of pro-coagulant proteases such as thrombin, factor Xa } \\
\text { and factor IXa; activity enhanced by heparin or heparan sulfate } \\
\text { Inactivator of the procoagulant protease thrombin; activated by dermatan sulfate in the } \\
\text { endothelial glycocalyx }\end{array}$ & 120 \\
Heparin cofactor II & Anticoagulant protein blocking activated factor VII and X & 38,49 \\
TFPI & Enzyme involved in breakdown of low density lipoproteins & 133 \\
LPL & Transports cholesterol and triglycerides through the circulation & 140 \\
LDL & Potent stimulator of angiogenesis, production of which is triggered by hypoxia & 92 \\
VEGF & Growth factor known to mediate in a lot of signaling pathways, including smooth & 64 \\
TGF $\beta 1 / 2$ & muscle cell differentiation and vascular tone and reactivity & 3,26 \\
FGF(r) & Growth factor (receptor) involved in endothelial cell proliferation and angiogenesis & 11 \\
Ec-SOD & Extracellular quencher of reactive oxygen species & \\
IL $2,3,4,5,7,8,12$, RANTES & Chemotaxis of leukocytes to the subendothelium; involved in arrest and diapedesis & $2,39,100,110,143$ \\
\hline
\end{tabular}

TFPI Tissue factor pathway inhibitor, $L P L$ lipoprotein lipase, $L D L$ low density lipoprotein, $V E G F$ vascular endothelial growth factor, $T G F \beta 1 / 2$ transforming growth factor $\beta 1$ or $\beta 2, F G F(r)$ fibroblast growth factor (receptor), ec-SOD extracellular superoxide dismutase, $I L$ interleukin, RANTES Regulated on Activation, Normal T Expressed and Secreted—also known as chemokine CCL5 
risks for atherothrombotic cardiovascular events. One of the hallmarks of diabetes is insulin absence or resistance and subsequent hyperglycemia, impairing the protective capacity of the vessel wall [73], and resulting in enhanced endothelial permeability [1] and impaired NO synthase function [20]. However, a common pathway leading to these vascular dysfunctions has not been identified. Recently, it was shown that the systemic glycocalyx volume of healthy volunteers, as assessed by comparing the intravascular distribution volume of a glycocalyx-permeable and a glycocalyximpermeable tracer, was halved within $6 \mathrm{~h}$ after induction of acute hyperglycemia [76]. Using the same methodology, the systemic glycocalyx volume in type 1 diabetics was found to be about half of that of healthy controls; it was further reduced in diabetics with microalbuminuria [75]. In the same study, plasma levels of hyaluronan and hyaluronidase were found to be elevated in patients with diabetes, reflecting increased synthesis and shedding of hyaluronan under hyperglycemic conditions. Both studies show that acute and long-standing hyperglycemia is associated with profound reduction of glycocalyx dimensions. It is tempting to speculate that this damage to the glycocalyx contributes to endothelial dysfunction in hyperglycemic conditions, which can be measured in nondiabetic subjects as well [118]. Further studies are needed to investigate whether glycocalyx perturbation is responsible for the (micro)vascular complications in diabetes.

\section{Ischemia/reperfusion}

Damage to tissues during a period of absent or decreased flow (total or partial ischemia) can paradoxically be exaggerated by restoration of blood flow (reperfusion). Although the severity of damage resulting from ischemia/ reperfusion varies between tissues, a common component of this pathologic process for all organs is microvascular dysfunction $[32,105]$. Endothelial cells play a central role and exhibit swelling and detachment from the basement membrane after ischemia/reperfusion [77]. Especially in postcapillary venules, endothelial cells suffer from increased oxidative stress [56], leukocytes adhere and transmigrate $[8,132]$, and vascular permeability increases [55]. These endothelial consequences of ischemia/reperfusion allude at involvement of the endothelial glycocalyx. Indeed, it was recently shown by Mulivor and Lipowsky [70] that intestinal ischemia/reperfusion led to significant reduction of glycocalyx thickness in rat mesenteric venules, most likely due to shedding of glycosaminoglycan chains. The effects of ischemia/reperfusion on the glycocalyx could be attenuated by blockade of xanthine-oxidoreductase, which is an endogenous reactive oxygen species (ROS) producing enzyme bound to heparan sulfate domains in the glycocalyx. This way, a central role for ROS in disruption and shedding of the glycocalyx in ischemia/reperfusion was established [97]. Infusion of exogenous hyaluronan to restore the glycocalyx or administration of pertussis toxin, which inhibits G-protein-mediated shedding of glycosaminoglycan chains, also reduced ischemia-/reperfusion-induced damage [70]. Together, these data hint at a role for the endothelial glycocalyx in the pathophysiology of ischemia-/reperfusion-induced tissue damage. However, its relative contribution to this process and the impact of possible therapeutical interventions are yet to be established $[6,122,134]$.

\section{Atherosclerosis}

Atherosclerosis is a large artery disease and typically requires high plasma levels of LDL to develop at predilection sites [34] that are marked by disturbed flow profiles. Subendothelial retention of atherogenic lipoproteins and subsequent inflammatory responses lead to the formation of subendothelial plaques $[60,93]$. The role of the endothelial glycocalyx in atherogenesis is, as yet, not well-established, but there are some interesting observations which point at its involvement.

In 2000, Vink and colleagues [128] showed that administration of clinically relevant doses of ox-LDL leads to a disruption of the glycocalyx in hamster cremaster muscle microcirculation and evokes local platelet adhesion. Co-infusion with SOD and catalase, enzymes catalyzing the dismutation of superoxide anion and the decomposition of hydrogen peroxide, abolished this effect of ox-LDL, implicating a role for oxygen-derived free radicals. Indeed, loss of glycocalyx results in shedding of endogenous protective enzymes, such as extracellular SOD, and increases the oxidative stress on endothelial cells. This was further illustrated by a recent study by van den Berg et al. [123], showing a reduction in glycocalyx dimensions due to a high-fat, high-cholesterol diet. Furthermore, an inverse relation between glycocalyx thickness and intimamedia ratio was found, reflecting a reduction of vasculoprotective capacity of the endothelial glycocalyx at sites with higher atherogenic risk. In healthy mice, regional variations were found showing a thinner glycocalyx in the internal carotid sinus region compared to the common carotid artery. Together, these data suggest that the endothelial glycocalyx is involved in the initiation and progression of the atherosclerotic process [74].

In summary, the endothelial glycocalyx appears to be perturbed in several vascular diseases. It remains to be elucidated whether glycocalyx perturbation is causally involved in the pathophysiology of these diseases. If so, restoration of the glycocalyx may be a therapeutic target of interest. Furthermore, identification of specific glycosaminoglycan domains involved in these diseases, as a platform 
for other substances or signaling pathways, might also prove to be of therapeutic value [4].

\section{Visualization techniques}

Because of the functional importance of the endothelial glycocalyx, development of direct visualization techniques is crucial to establish its exact role. The glycocalyx can be labeled by administration of specific markers that attach to one or more of its components, making them fluorescent or detectable. Preparation of (parts of) the vessel would then allow specific microscopic imaging of the endothelial glycocalyx. Regretfully, the glycocalyx is very vulnerable and easily disturbed or dehydrated during vessel handling and preparation protocols. As a result, glycocalyx dimensions are easily underestimated, which is illustrated by the first images of the glycocalyx, made by transmission electron microscopy (TEM) in 1966 with the use of the probe ruthenium red; glycocalyx thickness measured this way approximated $20 \mathrm{~nm}$ in capillaries [66]. Since then, many other attempts were made to image the glycocalyx using TEM. On bovine aorta endothelial cells under shear stress conditions of 3.0 Pa, the glycocalyx was reported to be $40 \mathrm{~nm}$ thick [121]. These dimensions did not comply with theoretical estimates predicting the glycocalyx to be up to $1 \mu \mathrm{m}$ thick [51]. Using a new staining protocol with Alcian blue 8GX, van den Berg et al. [124] recently applied TEM to measure endothelial glycocalyx dimensions in rat myocardial capillaries, which revealed that endothelial cells are covered by a $200-$ to $500-n m$ thick glycocalyx (Fig. 2a). Hyaluronidase treatment before fixation and staining resulted in significant reduction of this layer to $100-200 \mathrm{~nm}$. The groups of Haraldsson [37] and of Rostgaard and Qvortrup $[94,95]$ improved the TEM staining protocol using fluorocarbon-based oxygen carrying fixatives, revealing glycocalyces as thick as $60-200 \mathrm{~nm}$ in glomerular capillaries, and 50-100 $\mathrm{nm}$ in intestinal fenestrated capillaries. Apparently, the new staining and preparation protocols improved glycocalyx conservation in TEM experiments. However, TEM cannot be used in the in vivo situation.

Some 30 years after the first TEM images were made, Vink et al. [129] used intravital microscopy to visualize the endothelial glycocalyx in hamster cremaster muscle capillaries in vivo using indirect approaches. The glycocalyx was recognized as a red blood cell "exclusion zone" or "gap" between the flowing red blood cells and the endothelium. In addition, the plasma was labeled by a fluorescent dextran, and the glycocalyx then appeared as a plasma exclusion zone (Fig. 2b). Interestingly, no exclusion zone was found for rolling white blood cells, suggesting that they have the ability to compress the glycocalyx in these vessels, which complies with the estimated low stiffness of the glycocalyx $[33,106,138]$. Subtraction of the diameter of the plasma column from the anatomical internal diameter revealed the dimensions of the glycocalyx, which appeared to be 0.4 $0.5 \mu \mathrm{m}$ thick [129]. This method has been used in many studies since, primarily in the cremaster muscle microcirculation of hamsters $[35,36,130]$ or mice $[13,97]$. This tissue is suited for intravital microscopy because it is thin and translucent, allowing clear visualization of microvascular endothelial cells and flowing blood cells, with low or absent vessel wall motion (Fig. 2b). In addition, local flow velocities can be measured. However, the estimation of the glycocalyx thickness using intravital microscopy-based methods is indirect. Furthermore, intravital microscopy
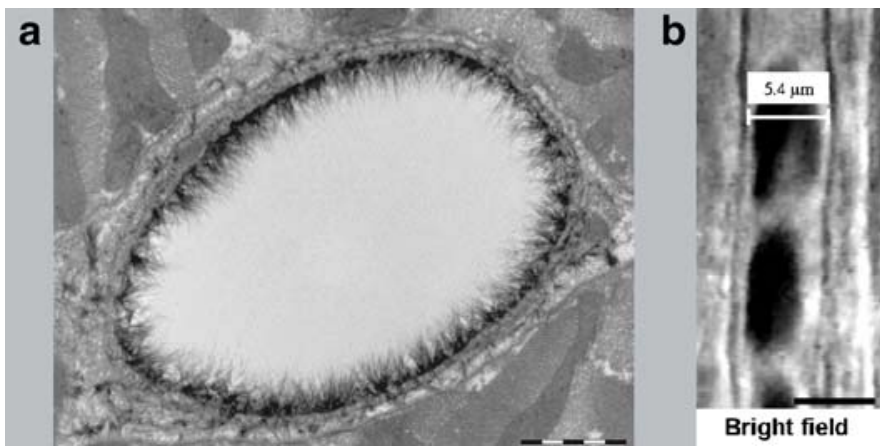

Fig. 2 Visualization of the endothelial glycocalyx with different microscopic techniques. a Endothelial glycocalyx of a rat left ventricular myocardial capillary stained with Alcian blue 8GX and visualized using electron microscopy. Bar represents $1 \mu \mathrm{m}$. Reproduced with permission from reference number [124]. b Intravital microscopic recording of the endothelial glycocalyx of a hamster cremaster muscle capillary. The anatomical diameter of $5.4 \mu \mathrm{m}$ is larger than the red blood cell column width (left pane) or the plasma column width (right pane) labeled with fluorescent dextran $(70 \mathrm{kD})$. This difference is caused by the presence of the endothelial

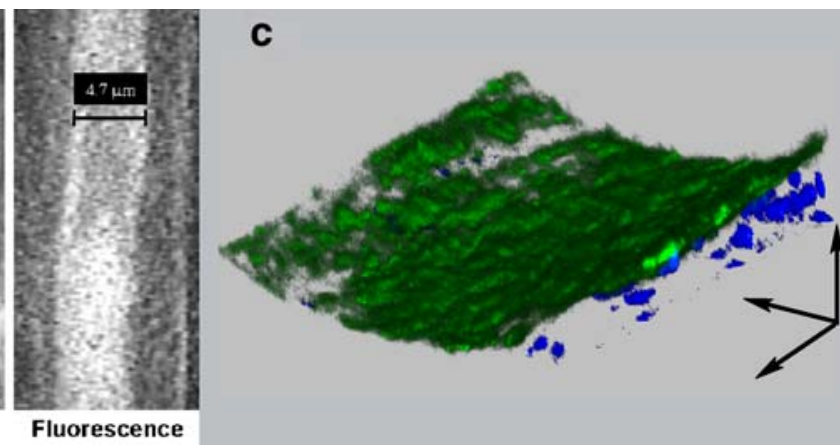

glycocalyx. The bar in the left pane represents $5 \mu \mathrm{m}$. Reproduced with permission from reference number [129]. c Endothelial glycocalyx of a mouse common carotid artery. 3D-reconstruction of a series of optical slices obtained with two-photon laser scanning microscopy showing part of the vessel wall. The intact vessel was perfused with FITC-labeled lectin ( $W G A$ ) to stain the endothelial glycocalyx (green) and SYTO 41 to label cell nuclei (blue). The arrows indicate the direction of the $X, Y$, and $Z$ axis. The scanned volume approximates $200 \times 200 \times 60 \mu^{3}$. For details on methodology see also reference number [67] 
cannot be applied to image the endothelial glycocalyx in larger vessels.

Direct visualization of the glycocalyx has been performed via several approaches, mostly using lectins which are proteins that bind specific disaccharide moieties of glycosaminoglycan chains $[5,24,70]$. Other labels include antibodies for heparan sulfate, syndecan-1 or hyaluronan $[24,70]$. When attaching these markers to a fluorescent probe, advanced microscopic techniques can be applied to visualize the glycocalyx. Confocal laser scanning microscopy (CLSM) enables optical sectioning with good optical resolution, allowing $3 \mathrm{D}$ reconstructions of the specimen. Lectin labeling of the glycocalyx of cultured human umbilical vein endothelial cells and subsequent CLSM imaging revealed a surface layer as thick as $2.5 \pm 0.5 \mu \mathrm{m}$ [5]. CLSM has also been used to detect concentration changes of fluorescently labeled lectins in the glycocalyx of fixated rat mesentery postcapillary venules in case of ischemia/reperfusion and inflammation [70]. Because larger vessels have thicker walls, which results in lower light penetration depths with significant loss of resolution at higher depths $(>40 \mu \mathrm{m})$ [127] due to increased scattering of signal, CLSM is less suitable for imaging of the glycocalyx in arteries.

A promising technique to directly visualize the glycocalyx in larger vessels, both ex vivo and in vivo, is two-photon laser scanning microscopy (TPLSM). TPLSM depends on excitation of a fluorophore by simultaneous uptake (i.e., within $10^{-18} \mathrm{~s}$ ) of two red photons, instead of one blue photon as in conventional fluorescence excitation. The use of long wavelength red photons reduces scattering, and hence, increases penetration depth into tissue. Excitation of the fluorophore and consequent fluorescence only occurs at the focal point of the illumination cone, as the probability of two-photon excitation depends on the squared intensity of the excitatory photons. Any light received by the photomultipliers has to originate from the focal position, so scattering of the emitted photons does not influence resolution and no pinholes are required. As a consequence, TPLSM offers good resolution and optical sectioning at reasonable acquisition speed, while bleaching and phototoxicity of the dyes is limited to the focal position. The combination of enhanced penetration depth, good resolution, optical sectioning, and low phototoxicity makes TPLSM a suitable technique to visualize the delicate endothelial glycocalyx in larger vessels. This idea was confirmed by a recent study by Megens and colleagues [67] in which the endothelial glycocalyx was imaged with TPLSM in intact mouse carotid arteries (Fig. 2c); the glycocalyx thickness was found to be $4.5 \pm 1.0 \mu \mathrm{m}$. As TPLSM is also applicable in vivo in rodents [127], it might prove to be a good approach of in vivo visualization of the glycocalyx in the macrocirculation of these animals.

\section{Conclusions}

Overlying the vascular endothelium, the glycocalyx is a membrane-bound mesh in which plasma-derived molecules integrate. It exerts a variety of functions, important in normal vascular physiology and also in vascular disease. Although data from experiments in microcirculation, and more recently, in macrocirculation strongly suggests a vasculoprotective role for the glycocalyx, research on this subject is hampered by lack of a good visualization technique. Twophoton laser scanning microscopy may prove to be a successful tool in achieving direct visualization of the glycocalyx in larger arteries in rodents, both ex vivo and in vivo, with the possibility to analyze focal variations in the composition or integrity of this layer.

Acknowledgements The authors thank Remco Megens for his support in the visualization of the glycocalyx with two-photon microscopy and Bernard van den Berg for providing his EM-picture. This research is supported by NWO grant \#902-16-276 and SenterNovem (BSIK 03033).

\section{References}

1. Algenstaedt P, Schaefer C, Biermann T, Hamann A, Schwarzloh B, Greten H, Ruther W, Hansen-Algenstaedt N (2003) Microvascular alterations in diabetic mice correlate with level of hyperglycemia. Diabetes 52:542-549

2. Ali S, Fritchley SJ, Chaffey BT, Kirby JA (2002) Contribution of the putative heparan sulfate-binding motif BBXB of RANTES to transendothelial migration. Glycobiology 12:535-543

3. Allen BL, Filla MS, Rapraeger AC (2001) Role of heparan sulfate as a tissue-specific regulator of FGF-4 and FGF receptor recognition. J Cell Biol 155:845-858

4. Ballinger ML, Nigro J, Frontanilla KV, Dart AM, Little PJ (2004) Regulation of glycosaminoglycan structure and atherogenesis. Cell Mol Life Sci 61:1296-1306

5. Barker AL, Konopatskaya O, Neal CR, Macpherson JV, Whatmore JL, Winlove CP, Unwin PR, Shore AC (2004) Observation and characterisation of the glycocalyx of viable human endothelial cells using confocal laser scanning microscopy. Phys Chem Chem Phys 6:1006-1011

6. Beresewicz A, Czarnowska E, Maczewski M (1998) Ischemic preconditioning and superoxide dismutase protect against endothelial dysfunction and endothelium glycocalyx disruption in the postischemic guinea-pig hearts. Mol Cell Biochem 186:87-97

7. Berndt MC, Shen Y, Dopheide SM, Gardiner EE, Andrews RK (2001) The vascular biology of the glycoprotein Ib-IX-V complex. Thromb Haemost 86:178-188

8. Beuk RJ, Heineman E, Tangelder GJ, Quaedackers JS, Marks WH, Lieberman JM, oude Egbrink MG (2000) Total warm ischemia and reperfusion impairs flow in all rat gut layers but increases leukocyte-vessel wall interactions in the submucosa only. Ann Surg 231:96-104

9. Bode L, Eklund EA, Murch S, Freeze HH (2005) Heparan sulfate depletion amplifies TNF-alpha-induced protein leakage in an in vitro model of protein-losing enteropathy. Am J Physiol Gastrointest Liver Physiol 288:G1015-G1023 
10. Bode L, Murch S, Freeze HH (2006) Heparan sulfate plays a central role in a dynamic in vitro model of protein-losing enteropathy. J Biol Chem 281:7809-7815

11. Bombeli T, Schwartz BR, Harlan JM (1998) Adhesion of activated platelets to endothelial cells: evidence for a GPIIbIIIa-dependent bridging mechanism and novel roles for endothelial intercellular adhesion molecule 1 (ICAM-1), alphavbeta3 integrin, and GPIbalpha. J Exp Med 187:329-339

12. Carey DJ (1997) Syndecans: multifunctional cell-surface coreceptors. Biochem J 327(Pt 1):1-16

13. Constantinescu AA, Vink H, Spaan JA (2003) Endothelial cell glycocalyx modulates immobilization of leukocytes at the endothelial surface. Arterioscler Thromb Vasc Biol 23:1541-1547

14. Curry FR (2005) Microvascular solute and water transport. Microcirculation 12:17-31

15. Das S, Deb TB, Kumar R, Datta K (1997) Multifunctional activities of human fibroblast $34-\mathrm{kDa}$ hyaluronic acid-binding protein. Gene 190:223-225

16. Davies PF (1995) Flow-mediated endothelial mechanotransduction. Physiol Rev 75:519-560

17. Desjardins C, Duling BR (1990) Heparinase treatment suggests a role for the endothelial cell glycocalyx in regulation of capillary hematocrit. Am J Physiol 258:H647-H654

18. Dewey CF Jr, Bussolari SR, Gimbrone MA Jr, Davies PF (1981) The dynamic response of vascular endothelial cells to fluid shear stress. J Biomech Eng 103:177-185

19. Dole VS, Bergmeier W, Mitchell HA, Eichenberger SC, Wagner DD (2005) Activated platelets induce Weibel-Palade-body secretion and leukocyte rolling in vivo: role of P-selectin. Blood 106:2334-2339

20. Du XL, Edelstein D, Dimmeler S, Ju Q, Sui C, Brownlee M (2001) Hyperglycemia inhibits endothelial nitric oxide synthase activity by posttranslational modification at the Akt site. J Clin Invest 108:1341-1348

21. Egbrink MG, Van Gestel MA, Broeders MA, Tangelder GJ, Heemskerk JM, Reneman RS, Slaaf DW (2005) Regulation of microvascular thromboembolism in vivo. Microcirculation $12: 287-300$

22. Esko JD, Selleck SB (2002) Order out of chaos: assembly of ligand binding sites in heparan sulfate. Annu Rev Biochem 71:435-471

23. Evanko SP, Wight TN (1999) Intracellular localization of hyaluronan in proliferating cells. J Histochem Cytochem 47:1331-1342

24. Florian JA, Kosky JR, Ainslie K, Pang Z, Dull RO, Tarbell JM (2003) Heparan sulfate proteoglycan is a mechanosensor on endothelial cells. Circ Res 93:e136-e142

25. Fransson LA, Belting M, Cheng F, Jonsson M, Mani K, Sandgren S (2004) Novel aspects of glypican glycobiology. Cell Mol Life Sci 61:1016-1024

26. Fromm JR, Hileman RE, Weiler JM, Linhardt RJ (1997) Interaction of fibroblast growth factor-1 and related peptides with heparan sulfate and its oligosaccharides. Arch Biochem Biophys 346:252-262

27. Funderburgh JL (2000) Keratan sulfate: structure, biosynthesis, and function. Glycobiology 10:951-958

28. Ghitescu L, Robert M (2002) Diversity in unity: the biochemical composition of the endothelial cell surface varies between the vascular beds. Microsc Res Tech 57:381-389

29. Gibson RM, Kansas GS, Tedder TF, Furie B, Furie BC (1995) Lectin and epidermal growth factor domains of P-selectin at physiologic density are the recognition unit for leukocyte binding. Blood 85:151-158

30. Gouverneur M, Spaan JA, Pannekoek H, Fontijn RD, Vink H (2006) Fluid shear stress stimulates incorporation of hyaluronan into endothelial cell glycocalyx. Am J Physiol Heart Circ Physiol 290:H452-H458
31. Grammatikakis N, Grammatikakis A, Yoneda M, Yu Q, Banerjee SD, Toole BP (1995) A novel glycosaminoglycan-binding protein is the vertebrate homologue of the cell cycle control protein, Cdc37. J Biol Chem 270:16198-16205

32. Granger DN (1999) Ischemia-reperfusion: mechanisms of microvascular dysfunction and the influence of risk factors for cardiovascular disease. Microcirculation 6:167-178

33. Han YF, Weinbaum S, Spaan JAE, Vink H (2006) Largedeformation analysis of the elastic recoil of fibre layers in a Brinkman medium with application to the endothelial glycocalyx. J Fluid Mech 554:217-235

34. Hansson GK (2005) Inflammation, atherosclerosis, and coronary artery disease. N Engl J Med 352:1685-1695

35. Henry CB, Duling BR (1999) Permeation of the luminal capillary glycocalyx is determined by hyaluronan. Am J Physiol 277:H508-H514

36. Henry CB, Duling BR (2000) TNF-alpha increases entry of macromolecules into luminal endothelial cell glycocalyx. Am J Physiol Heart Circ Physiol 279:H2815-H2823

37. Hjalmarsson C, Johansson BR, Haraldsson B (2004) Electron microscopic evaluation of the endothelial surface layer of glomerular capillaries. Microvasc Res 67:9-17

38. Ho G, Broze GJ Jr, Schwartz AL (1997) Role of heparan sulfate proteoglycans in the uptake and degradation of tissue factor pathway inhibitor-coagulation factor Xa complexes. J Biol Chem 272:16838-16844

39. Hoogewerf AJ, Kuschert GS, Proudfoot AE, Borlat F, ClarkLewis I, Power CA, Wells TN (1997) Glycosaminoglycans mediate cell surface oligomerization of chemokines. Biochemistry 36:13570-13578

40. Hu X, Weinbaum S (1999) A new view of Starling's hypothesis at the microstructural level. Microvasc Res 58:281-304

41. Huang MT, Mason JC, Birdsey GM, Amsellem V, Gerwin N, Haskard DO, Ridley AJ, Randi AM (2005) Endothelial intercellular adhesion molecule (ICAM)-2 regulates angiogenesis. Blood 106:1636-1643

42. Huxley VH, Curry FE (1991) Differential actions of albumin and plasma on capillary solute permeability. Am J Physiol 260: H1645-H1654

43. Ihrcke NS, Wrenshall LE, Lindman BJ, Platt JL (1993) Role of heparan sulfate in immune system-blood vessel interactions. Immunol Today 14:500-505

44. Iozzo RV (1994) Perlecan: a gem of a proteoglycan. Matrix Biology 14:203-208

45. Jacob M, Bruegger D, Rehm M, Welsch U, Conzen P, Becker BF (2006) Contrasting effects of colloid and crystalloid resuscitation fluids on cardiac vascular permeability. Anesthesiology 104:1223-1231

46. Janssen GH, Tangelder GJ, Oude Egbrink MG, Reneman RS (1994) Spontaneous leukocyte rolling in venules in untraumatized skin of conscious and anesthetized animals. Am J Physiol 267: H1199-H1204

47. Jung U, Ley K (1997) Regulation of E-selectin, P-selectin, and intercellular adhesion molecule 1 expression in mouse cremaster muscle vasculature. Microcirculation 4:311-319

48. Kansas GS, Saunders KB, Ley K, Zakrzewicz A, Gibson RM, Furie BC, Furie B, Tedder TF (1994) A role for the epidermal growth factor-like domain of $\mathrm{P}$-selectin in ligand recognition and cell adhesion. J Cell Biol 124:609-618

49. Kato H (2002) Regulation of functions of vascular wall cells by tissue factor pathway inhibitor: basic and clinical aspects. Arterioscler Thromb Vasc Biol 22:539-548

50. Kinsella MG, Bressler SL, Wight TN (2004) The regulated synthesis of versican, decorin, and biglycan: extracellular matrix proteoglycans that influence cellular phenotype. Crit Rev Eukaryot Gene Expr 14:203-234 
51. Klitzman B, Duling BR (1979) Microvascular hematocrit and red cell flow in resting and contracting striated muscle. Am J Physiol 237:H481-H490

52. Klitzman B, Johnson PC (1982) Capillary network geometry and red cell distribution in hamster cremaster muscle. Am J Physiol 242:H211-H219

53. Koedam JA, Cramer EM, Briend E, Furie B, Furie BC, Wagner DD (1992) P-selectin, a granule membrane protein of platelets and endothelial cells, follows the regulated secretory pathway in AtT-20 cells. J Cell Biol 116:617-625

54. Kresse H, Hausser H, Schonherr E, Bittner K (1994) Biosynthesis and interactions of small chondroitin/dermatan sulphate proteoglycans. Eur J Clin Chem Clin Biochem 32:259-264

55. Kupinski AM, Shah DM, Bell DR (1993) Transvascular albumin flux in rabbit hindlimb after tourniquet ischemia. Am J Physiol 264:H901-H908

56. Kurose I, Argenbright LW, Wolf R, Lianxi L, Granger DN (1997) Ischemia/reperfusion-induced microvascular dysfunction: role of oxidants and lipid mediators. Am J Physiol 272:H2976-H2982

57. Laurent TC, Fraser JR (1992) Hyaluronan. Faseb J 6:2397-2404

58. Lee JY, Spicer AP (2000) Hyaluronan: a multifunctional, megaDalton, stealth molecule. Curr Opin Cell Biol 12:581-586

59. Li Q, Bolli R, Qiu Y, Tang XL, Murphree SS, French BA (1998) Gene therapy with extracellular superoxide dismutase attenuates myocardial stunning in conscious rabbits. Circulation 98:14381448

60. Libby P (2002) Inflammation in atherosclerosis. Nature 420:868-874

61. Lin X (2004) Functions of heparan sulfate proteoglycans in cell signaling during development. Development 131:6009-6021

62. Lipowsky HH (2005) Microvascular rheology and hemodynamics. Microcirculation 12:5-15

63. Lipowsky HH, Kovalcheck S, Zweifach BW (1978) The distribution of blood rheological parameters in the microvasculature of cat mesentery. Circ Res 43:738-749

64. Lopez-Casillas F, Wrana JL, Massague J (1993) Betaglycan presents ligand to the TGF beta signaling receptor. Cell 73:1435-1444

65. Lopez JA (1994) The platelet glycoprotein Ib-IX complex. Blood Coagul Fibrinolysis 5:97-119

66. Luft JH (1966) Fine structures of capillary and endocapillary layer as revealed by ruthenium red. Fed Proc 25:1773-1783

67. Megens RTA, Reitsma S, Schiffers PHM, Hilgers RHP, De Mey JGR, Slaaf DW, oude Egbrink MGA, van Zandvoort MAMJ (2007) Two-photon microscopy of vital murine elastic and muscular arteries. J Vasc Res 44:87-98

68. Michel CC (1997) Starling: the formulation of his hypothesis of microvascular fluid exchange and its significance after 100 years. Exp Physiol 82:1-30

69. Mochizuki S, Vink H, Hiramatsu O, Kajita T, Shigeto F, Spaan JA, Kajiya F (2003) Role of hyaluronic acid glycosaminoglycans in shear-induced endothelium-derived nitric oxide release. Am J Physiol Heart Circ Physiol 285:H722-H726

70. Mulivor AW, Lipowsky HH (2004) Inflammation- and ischemiainduced shedding of venular glycocalyx. Am J Physiol Heart Circ Physiol 286:H1672-H1680

71. Muller AM, Hermanns MI, Cronen C, Kirkpatrick CJ (2002) Comparative study of adhesion molecule expression in cultured human macro- and microvascular endothelial cells. Exp Mol Pathol 73:171-180

72. Nandi A, Estess P, Siegelman MH (2000) Hyaluronan anchoring and regulation on the surface of vascular endothelial cells is mediated through the functionally active form of CD44. J Biol Chem 275:14939-14948

73. Nathan DM, Lachin J, Cleary P, Orchard T, Brillon DJ, Backlund JY, O'Leary DH, Genuth S (2003) Intensive diabetes therapy and carotid intima-media thickness in type 1 diabetes mellitus. $\mathrm{N}$ Engl J Med 348:2294-2303

74. Nieuwdorp M, Meuwese MC, Vink H, Hoekstra JB, Kastelein JJ, Stroes ES (2005) The endothelial glycocalyx: a potential barrier between health and vascular disease. Curr Opin Lipidol 16:507-511

75. Nieuwdorp M, Mooij HL, Kroon J, Atasever B, Spaan JA, Ince C, Holleman F, Diamant M, Heine RJ, Hoekstra JB, Kastelein JJ, Stroes ES, Vink H (2006) Endothelial glycocalyx damage coincides with microalbuminuria in type 1 diabetes. Diabetes 55:1127-1132

76. Nieuwdorp M, van Haeften TW, Gouverneur MC, Mooij HL, van Lieshout MH, Levi M, Meijers JC, Holleman F, Hoekstra JB, Vink H, Kastelein JJ, Stroes ES (2006) Loss of endothelial glycocalyx during acute hyperglycemia coincides with endothelial dysfunction and coagulation activation in vivo. Diabetes 55:480-486

77. Oliver MG, Specian RD, Perry MA, Granger DN (1991) Morphologic assessment of leukocyte-endothelial cell interactions in mesenteric venules subjected to ischemia and reperfusion. Inflammation 15:331-346

78. oude Egbrink MG, Janssen GH, Ookawa K, Slaaf DW, Reneman RS, Wehrens XH, Maaijwee KJ, Ohshima N, Struijker Boudier HA, Tangelder GJ (2002) Especially polymorphonuclear leukocytes, but also monomorphonuclear leukocytes, roll spontaneously in venules of intact rat skin: involvement of E-selectin. J Invest Dermatol 118:323-326

79. Pappenheimer JR, Renkin EM, Borrero LM (1951) Filtration, diffusion and molecular sieving through peripheral capillary membranes; a contribution to the pore theory of capillary permeability. Am J Physiol 167:13-46

80. Parker KA, Tollefsen DM (1985) The protease specificity of heparin cofactor II. Inhibition of thrombin generated during coagulation. J Biol Chem 260:3501-3505

81. Patel KD, Nollert MU, McEver RP (1995) P-selectin must extend a sufficient length from the plasma membrane to mediate rolling of neutrophils. J Cell Biol 131:1893-1902

82. Perrimon N, Bernfield M (2000) Specificities of heparan sulphate proteoglycans in developmental processes. Nature 404:725-728

83. Pries AR, Ley K, Gaehtgens P (1986) Generalization of the Fahraeus principle for microvessel networks. Am J Physiol 251: H1324-H1332

84. Pries AR, Secomb TW (2003) Rheology of the microcirculation. Clin Hemorheol Microcirc 29:143-148

85. Pries AR, Secomb TW (2005) Microvascular blood viscosity in vivo and the endothelial surface layer. Am J Physiol Heart Circ Physiol 289:H2657-H2664

86. Pries AR, Secomb TW, Gaehtgens P (2000) The endothelial surface layer. Pflugers Arch 440:653-666

87. Quinsey NS, Greedy AL, Bottomley SP, Whisstock JC, Pike RN (2004) Antithrombin: in control of coagulation. Int J Biochem Cell Biol 36:386-389

88. Raman R, Sasisekharan V, Sasisekharan R (2005) Structural insights into biological roles of protein-glycosaminoglycan interactions. Chem Biol 12:267-277

89. Rapraeger A (1989) Transforming growth factor (type beta) promotes the addition of chondroitin sulfate chains to the cell surface proteoglycan (syndecan) of mouse mammary epithelia. J Cell Biol 109:2509-2518

90. Rapraeger A, Jalkanen M, Endo E, Koda J, Bernfield M (1985) The cell surface proteoglycan from mouse mammary epithelial cells bears chondroitin sulfate and heparan sulfate glycosaminoglycans. J Biol Chem 260:11046-11052

91. Rehm M, Zahler S, Lotsch M, Welsch U, Conzen P, Jacob M, Becker BF (2004) Endothelial glycocalyx as an additional barrier determining extravasation of $6 \%$ hydroxyethyl starch or $5 \%$ 
albumin solutions in the coronary vascular bed. Anesthesiology 100:1211-1223

92. Robinson CJ, Stringer SE (2001) The splice variants of vascular endothelial growth factor (VEGF) and their receptors. J Cell Sci 114:853-865

93. Ross R (1999) Atherosclerosis-an inflammatory disease. N Engl J Med 340:115-126

94. Rostgaard J, Qvortrup K (1997) Electron microscopic demonstrations of filamentous molecular sieve plugs in capillary fenestrae. Microvasc Res 53:1-13

95. Rostgaard J, Qvortrup K (2002) Sieve plugs in fenestrae of glomerular capillaries - site of the filtration barrier? Cells Tissues Organs 170:132-138

96. Rubanyi GM, Romero JC, Vanhoutte PM (1986) Flow-induced release of endothelium-derived relaxing factor. Am J Physiol 250:H1145-H1149

97. Rubio-Gayosso I, Platts SH, Duling BR (2006) Reactive oxygen species mediate modification of glycocalyx during ischemia-reperfusion injury. Am J Physiol Heart Circ Physiol 290:H2247-H2256

98. Ruegg C, Mariotti A (2003) Vascular integrins: pleiotropic adhesion and signaling molecules in vascular homeostasis and angiogenesis. Cell Mol Life Sci 60:1135-1157

99. Ruggeri ZM (2003) Von Willebrand factor, platelets and endothelial cell interactions. J Thromb Haemost 1:1335-1342

100. Salek-Ardakani S, Arrand JR, Shaw D, Mackett M (2000) Heparin and heparan sulfate bind interleukin-10 and modulate its activity. Blood 96:1879-1888

101. Sarelius IH, Duling BR (1982) Direct measurement of microvessel hematocrit, red cell flux, velocity, and transit time. Am J Physiol 243:H1018-H1026

102. Sasaki K, Okouchi Y, Rothkotter HJ, Pabst R (1998) Threedimensional distribution of intercellular adhesion molecule-1 on lymphocytes in the high endothelial venule analyzed by backscatter electron imaging. Acta Anat (Basel) 162:33-39

103. Scott JE, Heatley F (1999) Hyaluronan forms specific stable tertiary structures in aqueous solution: a 13C NMR study. Proc Natl Acad Sci USA 96:4850-4855

104. Scott JE, Thomlinson AM, Prehm P (2003) Supramolecular organization in streptococcal pericellular capsules is based on hyaluronan tertiary structures. Exp Cell Res 285:1-8

105. Seal JB, Gewertz BL (2005) Vascular dysfunction in ischemiareperfusion injury. Ann Vasc Surg 19:572-584

106. Secomb TW, Hsu R, Pries AR (1998) A model for red blood cell motion in glycocalyx-lined capillaries. Am J Physiol 274: H1016-H1022

107. Shimada K, Kobayashi M, Kimura S, Nishinaga M, Takeuchi K, Ozawa T (1991) Anticoagulant heparin-like glycosaminoglycans on endothelial cell surface. Jpn Circ J 55:1016-1021

108. Sperandio M (2006) Selectins and glycosyltransferases in leukocyte rolling in vivo. Febs J 273:4377-4389

109. Sperandio M, Ley K (2005) The physiology and pathophysiology of P-selectin. Mod Asp Immunobiol 15:24-26

110. Spillmann D, Witt D, Lindahl U (1998) Defining the interleukin8-binding domain of heparan sulfate. J Biol Chem 273:1548715493

111. Springer TA (1990) Adhesion receptors of the immune system. Nature 346:425-434

112. Starling EH (1896) On the absorption of fluids from the connective tissue spaces. J Physiol 19:312-326

113. Stewart RJ, Kashour TS, Marsden PA (1996) Vascular endothelial platelet endothelial adhesion molecule-1 (PECAM-1) expression is decreased by TNF-alpha and IFN-gamma. Evidence for cytokineinduced destabilization of messenger ribonucleic acid transcripts in bovine endothelial cells. J Immunol 156:1221-1228

114. Sugahara K, Mikami T, Uyama T, Mizuguchi S, Nomura K, Kitagawa H (2003) Recent advances in the structural biology of chondroitin sulfate and dermatan sulfate. Curr Opin Struct Biol 13:612-620

115. Tan L, Kowalska MA, Romo GM, Lopez JA, Darzynkiewicz Z, Niewiarowski S (1999) Identification and characterization of endothelial glycoprotein Ib using viper venom proteins modulating cell adhesion. Blood 93:2605-2616

116. Tarbell JM, Pahakis MY (2006) Mechanotransduction and the glycocalyx. J Intern Med 259:339-350

117. Tarbell JM, Weinbaum S, Kamm RD (2005) Cellular fluid mechanics and mechanotransduction. Ann Biomed Eng 33:1719-1723

118. Title LM, Cummings PM, Giddens K, Nassar BA (2000) Oral glucose loading acutely attenuates endothelium-dependent vasodilation in healthy adults without diabetes: an effect prevented by vitamins C and E. J Am Coll Cardiol 36:2185-2191

119. Tkachenko E, Rhodes JM, Simons M (2005) Syndecans: new kids on the signaling block. Circ Res 96:488-500

120. Tovar AM, de Mattos DA, Stelling MP, Sarcinelli-Luz BS, Nazareth RA, Mourao PA (2005) Dermatan sulfate is the predominant antithrombotic glycosaminoglycan in vessel walls: implications for a possible physiological function of heparin cofactor II. Biochim Biophys Acta 1740:45-53

121. Ueda A, Shimomura M, Ikeda M, Yamaguchi R, Tanishita K (2004) Effect of glycocalyx on shear-dependent albumin uptake in endothelial cells. Am J Physiol Heart Circ Physiol 287: H2287-H2294

122. van den Berg B, Vink H (2006) Glycocalyx perturbation: cause or consequence of damage to the vasculature? Am J Physiol Heart Circ Physiol 290:H2174-H2175

123. van den Berg BM, Spaan JA, Rolf TM, Vink H (2006) Atherogenic region and diet diminish glycocalyx dimension and increase intima-to-media ratios at murine carotid artery bifurcation. Am J Physiol Heart Circ Physiol 290:H915-H920

124. van den Berg BM, Vink H, Spaan JA (2003) The endothelial glycocalyx protects against myocardial edema. Circ Res 92:592-594

125. van Haaren PM, VanBavel E, Vink H, Spaan JA (2003) Localization of the permeability barrier to solutes in isolated arteries by confocal microscopy. Am J Physiol Heart Circ Physiol 285:H2848-H2856

126. van Haaren PM, VanBavel E, Vink H, Spaan JA (2005) Charge modification of the endothelial surface layer modulates the permeability barrier of isolated rat mesenteric small arteries. Am J Physiol Heart Circ Physiol 289:H2503-H2507

127. van Zandvoort M, Engels W, Douma K, Beckers L, Oude Egbrink M, Daemen M, Slaaf DW (2004) Two-photon microscopy for imaging of the (atherosclerotic) vascular wall: a proof of concept study. J Vasc Res 41:54-63

128. Vink H, Constantinescu AA, Spaan JA (2000) Oxidized lipoproteins degrade the endothelial surface layer: implications for platelet-endothelial cell adhesion. Circulation 101:1500-1502

129. Vink H, Duling BR (1996) Identification of distinct luminal domains for macromolecules, erythrocytes, and leukocytes within mammalian capillaries. Circ Res 79:581-589

130. Vink H, Duling BR (2000) Capillary endothelial surface layer selectively reduces plasma solute distribution volume. Am J Physiol Heart Circ Physiol 278:H285-H289

131. Vogl-Willis CA, Edwards IJ (2004) High-glucose-induced structural changes in the heparan sulfate proteoglycan, perlecan, of cultured human aortic endothelial cells. Biochim Biophys Acta 1672:36-45

132. Vollmar B, Glasz J, Menger MD, Messmer K (1995) Leukocytes contribute to hepatic ischemia/reperfusion injury via intercellular adhesion molecule-1-mediated venular adherence. Surgery 117:195-200

133. Wang CS, Hartsuck J, McConathy WJ (1992) Structure and functional properties of lipoprotein lipase. Biochim Biophys Acta 1123:1-17 
134. Ward BJ, Donnelly JL (1993) Hypoxia induced disruption of the cardiac endothelial glycocalyx: implications for capillary permeability. Cardiovasc Res 27:384-389

135. Weigel PH, Hascall VC, Tammi M (1997) Hyaluronan synthases. J Biol Chem 272:13997-14000

136. Weiler H, Isermann BH (2003) Thrombomodulin. J Thromb Haemost 1:1515-1524

137. Weinbaum S (1998) 1997 Whitaker distinguished lecture: models to solve mysteries in biomechanics at the cellular level; a new view of fiber matrix layers. Ann Biomed Eng 26:627-643

138. Weinbaum S, Zhang X, Han Y, Vink H, Cowin SC (2003) Mechanotransduction and flow across the endothelial glycocalyx. Proc Natl Acad Sci USA 100:7988-7995

139. Weninger W, Ulfman LH, Cheng G, Souchkova N, Quackenbush EJ, Lowe JB, von Andrian UH (2000) Specialized contributions by alpha(1,3)-fucosyltransferase-IV and FucT-VII during leukocyte rolling in dermal microvessels. Immunity 12:665-676

140. Wilsie LC, Orlando RA (2003) The low density lipoprotein receptorrelated protein complexes with cell surface heparan sulfate proteo- glycans to regulate proteoglycan-mediated lipoprotein catabolism. J Biol Chem 278:15758-15764

141. Wu G, Essex DW, Meloni FJ, Takafuta T, Fujimura K, Konkle BA, Shapiro SS (1997) Human endothelial cells in culture and in vivo express on their surface all four components of the glycoprotein Ib/IX/V complex. Blood 90:2660-2669

142. Xiong JP, Stehle T, Goodman SL, Arnaout MA (2003) Integrins, cations and ligands: making the connection. J Thromb Haemost 1:1642-1654

143. Yamashita K, Fukushima K (2004) The carbohydrate recognition by cytokines modulates their physiological activities. Glycoconj J 21:31-34

144. Zhang X, Adamson RH, Curry FR, Weinbaum S (2006) A 1-D model to explore the effects of tissue loading and tissue concentration gradients in the revised Starling principle. Am J Physiol Heart Circ Physiol 291:H2950-H2964

145. Zhuo L, Hascall VC, Kimata K (2004) Inter-alpha-trypsin inhibitor, a covalent protein-glycosaminoglycan-protein complex. J Biol Chem 279:38079-38082 